\title{
Expression and Function of FGF5 Isoform in Hair Growth
}

\author{
Seong Kyeong Jo, Sooil Kim, Young Ho Lee* \\ Department of Anatomy, College of Medicine, Chungnam National University, Daejeon, Korea
}

DOI: $10.36348 /$ sijap.2021.v04i01.001

| Received: 15.01.2021 | Accepted: 27.01.2021 | Published: 30.01.2021

*Corresponding author: Young Ho Lee

Abstract

In mammals, hair cycle occurs continuously in three cycles: anagen, catagen, telogen. One of the fibroblast growth factor (FGF) family, FGF5, have been known to act as an inhibitor of hair growth in the transition from anagen to catagen. The FGF5 gene is composed of a long form (FGF5) and a short form (FGF5s). We examined the effect of FGF5 isoform on hair growth in the cultured keratinocytes. To analyze the effect of FGF5 isoform the keratinocytes, we overexpressed FGF5 isoform and gene expression change was observed with RT-PCR. Expression of hepatic growth factor (HGF) gene was increased when FGF5s was overexpressed by adenovirus (Ad) in keratinocytes. BMP6 tend to be decreased in the group transfected with Ad/FGF5 virus than in the control group. Taken together, FGF5s might activate HGF in hair growth and FGF5 may inhibit BMP6 expression in hair growth suppression.

Keywords: Hair growth, Fibroblast growth factor 5, Hepatic growth factor, Bone morphogenic protein 6, Keratinocyte.

Copyright (C) 2021 The Author(s): This is an open-access article distributed under the terms of the Creative Commons Attribution 4.0 International License (CC BY-NC 4.0) which permits unrestricted use, distribution, and reproduction in any medium for non-commercial use provided the original author and source are credited.

\section{INTRODUCTION}

Hair-bearing mammals produce hair through a continuous hair growth cycle. Hair growth cycle consists of three stage; anagen, catagen, and telogen [1]. Hair follicles are composed of epithelial cells and mesenchymal cells, and the interaction between these two cells is known to play an important role during the hair cycle [2]. Various chemokines act in the hair growth cycle to regulate hair growth. For example, epidermal growth factor (EGF) [3, 4], insulin-like growth factor-I (IGF-1), fibroblast growth factor (FGF) and so on $[5,6]$.

The FGF family is important for human hair follicle development and epidermal differentiation and proliferation [7]. Among them, FGF1, FGF2, FGF5 and their receptors are all in or adjacent to the hair follicle $[7,8]$. FGF2 has a positive effect on the hair growth cycle in mice [9], and FGF5 has an inhibitory effect on hair growth [10]. And FGF7 is located at the dermal papilla cells, so that hair germ cells proliferate and induce a new hair growth cycle $[11,12]$.

FGF5 gene was initially reported as one of the oncogenes [13], but it was classified as the FGF family because it has high homology with FGF [14]. FGF5 consists of 3 exons, and the FGF5 gene is divided into long FGF5 (FGF5-longform, FGF5) and short FGF5 (FGF5-shortform, FGF5s) depending on the presence or absence of exon 2 [9, 15]. Long FGF5 (FGF5) is composed of three exons, short FGF5 (FGF5s) is composed of exon 1 and a part of exon 3 due to a frame shift and a stop codon initially appearing [15]. In addition, FGF5 gene has been reported to regulate the degenerative phase in the late growth phase of the mammalian hair cycle $[10,16]$.

It was observed that the FGF5 gene-deficient mice had abnormally long-lasting growth phase VI during the hair cycle [10]. In addition, FGF5s plays a role as an inhibitor of long FGF5 [17, 18], and it has been reported that it regulates the transition from growth phase to degenerative phase in the dermal papilla of cashmere goats. FGF5 gene was observed in the outer root sheath of human hair. FGF5 gene has recently been observed as a potentially important factor in alopecia [16].

The aim of this study to find out how each of the FGF5 isoform in the hair works using overexpression of FGF5 isoforms in the cultured keratinocytes.

\section{MATERIALS \& METHODS Cell Culture}

Keratinocyte cells were cultured according to the previously reported method $[19,20]$. SVKC, a keratinocyte cell line, was subcultured and maintained using Keratinocyte-SFM (Gibco, Gaithersburg, MD, USA). In addition, 293A cells were subcultured and 
maintained with $10 \%$ fatal bovine serum (Welgene, Korea) in DMEM (Welgene, Korea).

\section{Viral vector amplification}

After the 293A cells were subculture in DMEM culture media, the virus was infected with Keratinocyte-SFM media before 293A cells were infected with the virus. Thereafter, 293A cells were removed from the $95 \%$ cell culture dish, they were transferred to a tube and the freezing and thawing processes were repeated a total of 5 times. And after centrifugation at $3,000 \mathrm{rpm}$ for 10 minutes, the supernatant was used.

\section{Transfection of the genes associates with hair growth}

Adenovirus/LacZ (Ad/LacZ), Ad/FGF5, Ad/FGF5s, green fluorescent protein/adenovirus (GFPAd), GFP-Ad/FGF5, and GFP-Ad/FGF5s were each transfected with SVKC for 48 hours. And virus transfection was observed at 24 hours and 48 hours using a fluorescence microscope.

\section{RNA Extraction}

After removing the culture medium of SVKC, washed it with $1 \mathrm{M}$ PBS, added $300 \mu \mathrm{l}$ of Tri-Reagent (MRC, Cincinnati, USA) and reacted on ice for 10 minutes, and then added $60 \mu \mathrm{l}$ of chloroform (SigmaAldrich, Louis, MO, USA). After adding and sufficiently mixing, usual method was used for RNA extraction. After drying the pellet, diethyl pyrocarbonate was diluted to $0.1 \%$ using distilled water to dissolve the pellet, and then quantified using a UV spectrophotometer.

\section{RT-PCR}

RNA $(2 \mu \mathrm{g})$ was made into cDNA using MMLV reverse transcriptase. A polymerase chain reaction (PCR) was performed to prepare a primer for the gene to be examined (Table-1). Reverse Transcriptase (Promega, Madison, WI, USA) and an oligo (dT) primer was used in this experiment. Subsequently, $120 \mathrm{ng}$ of the cDNA was used in PCR amplification to assess the expression of genes associated with hair growth. To normalize for differences in cDNA loading, primers designed to amplify glyceraldehyde-3-phosphate dehydrogenase (GAPDH) were used.

\section{STATISTICAL ANALYSIS}

One-way ANOVA and Newman-Keuls posthoc test were performed to determine the difference in mRNA expression between the control group and the experimental group, and statistical significance was determined to be significant when the $\mathrm{P}$ value was less than 0.05 .

\section{RESULT}

In order to analyze whether the virus is infected with SVKC into the cells, Ad/GFP-FGF5 and Ad/GFP-FGF5s viruses were infected for 48 hours, respectively, and observed under a microscope at 24 hours and 48 hours. As a result, it was confirmed that the virus was infected into SVKC. After infecting the cells with Ad/FGF5, Ad/FGF5s, Ad/GFP-FGF5, and Ad/GFP-FGF5s for 48 hours, the amount of FGF5 gene expression was confirmed through reverse transcription polymerase chain reaction. The expression pattern of FGF5 in the group infected with Ad/GFP-FGF5 and Ad/GFP-FGF5s was observed in a similar pattern in the group infected with Ad/FGF5 and Ad/FGF5s. Compared to the control group of each of the two groups, the amount of expression was increased in the group infected with FGF5 and FGF5s virus (Figure-1).

\section{Gene expression associated with hair growth after overexpression of FGF5 isoform}

The genes related to hair growth was identified with cDNA infected with Ad/FGF5 and Ad/FGF5s viruses in SVKC. It was observed that genes involved in hair growth, HGF was significantly increased in the group infected with Ad/FGF5s viruses than in the control and Ad/FGF5 groups. However, expression of the genes, stem cell factor (SCF), Dickkopf-related protein (DKK) 1 and FGF2 in the experimental groups were not changed significantly compared with the control group (Figure-2).

Genes directly associated with hair growth, keratin (KRT5), keratin 14 (KRT14), and bone morphogenic protein 6 (BMP6) which promoting the telogen-anagen transition in vivo, was evaluated in the SVKC infected with Ad/FGF5 and Ad/FGF5s viruses. BMP6 tend to be decreased (statistically not significant, $\mathrm{p}=0.08)$ in the group infected with Ad/FGF5 virus, compared with the control and Ad/FGF5s groups. Expression of KRT5 and KRT14 genes in the experimental groups were not changed significantly compared with the control group (Figure-3). 
Table-1: List of primer sequences used in RT-RCR

\begin{tabular}{|l|l|}
\hline Gene & Primer sequence \\
\hline $\begin{array}{l}\text { FGF5 (upper band : long form) } \\
\text { (lower band : short form) }\end{array}$ & $\begin{array}{l}\text { F 5'-AGTCAATGGATCCCACGAAG-3' } \\
\text { R 5'-TCATCTGTGAACTTGGC-3' }\end{array}$ \\
\hline HGF & $\begin{array}{l}\text { F 5'-TGGTAAAGGACGCAGCTACA-3' } \\
\text { R 5'-GCGTACCTCTGGATTGCTTG-3' }\end{array}$ \\
\hline SCF & $\begin{array}{l}\text { F 5'-CGGGATGGATGTTTTGCCAA-3' } \\
\text { R 5'-TGGGTTCTGGGCTCTTGAAT-3' }\end{array}$ \\
\hline FGF2 & F 5'-AGGAGTGTGTGCTAACCGTT-3' \\
& R 5'-CAGTTCGTTTCAGTGCCACA-3' \\
\hline DKK1 & F 5'-ACCAGCTATCCAAATGCAGTG-3' \\
& R 5'-TGCAATCACAGGGGAGTTCC-3' \\
\hline KRT5 & F 5'-GCGTACCACTGCTGAGAATG-3' \\
& R 5'-TGATACCAGGACTCGGCTTC-3' \\
\hline KRT14 & F 5'-CTGTCTCATCCTCCCGCTTC-3' \\
& R 5'-AGGCGGTCATTGAGGTTCTG-3' \\
\hline BMP6 & F 5'-CCTTACGACAAGCAGCCCTT-3' \\
& R 5'-TGGGTGCAATGATCCAGTCC-3' \\
\hline
\end{tabular}

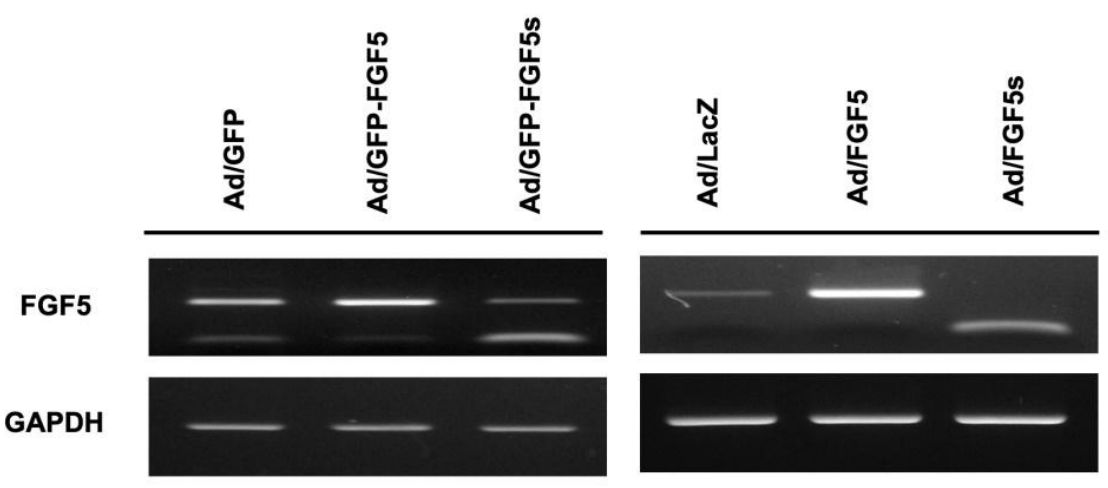

Fig-1: The cells were infected with GFP-Ad/FGF5, GFP-Ad/FGF5s, Ad/FGF5 and Ad/FGF5s for 48 hours and then confirmed by RT-PCR

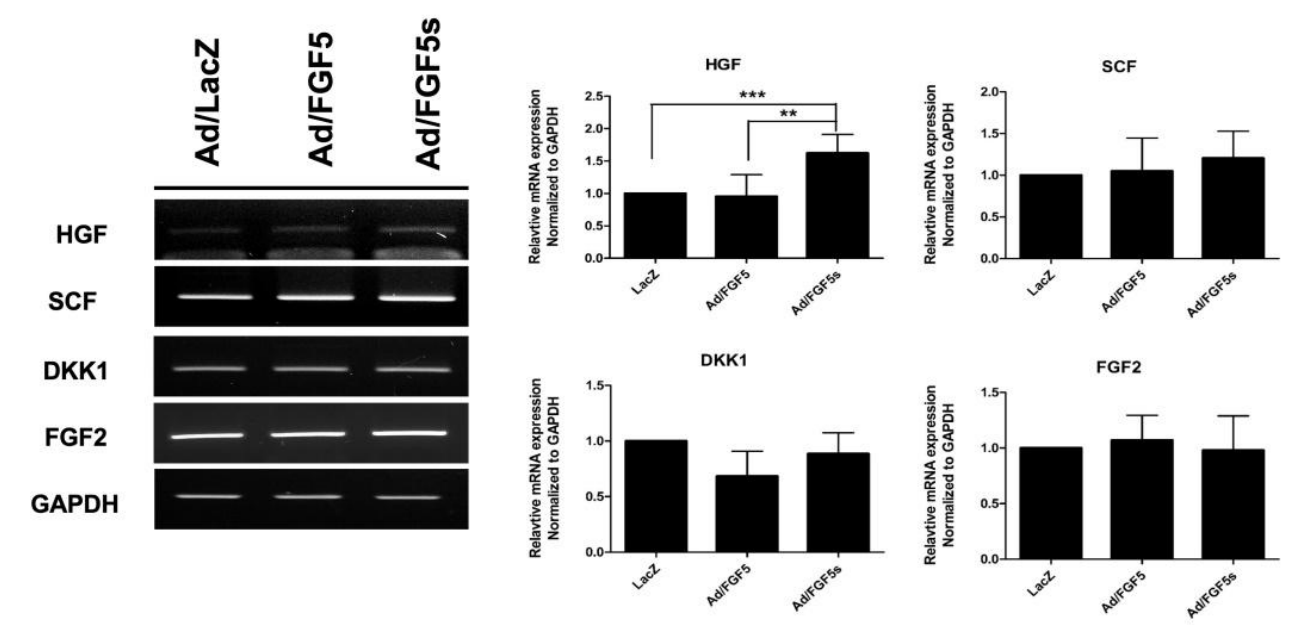

Fig-2: Gene expression regulating hair growth after FGF5 isoform overexpression in the SVKC. The graph data are shown the means \pm SD of three independent experiments. Statistically significant differences are indicated by $* * p<0.01, * * * p<0.001$ 


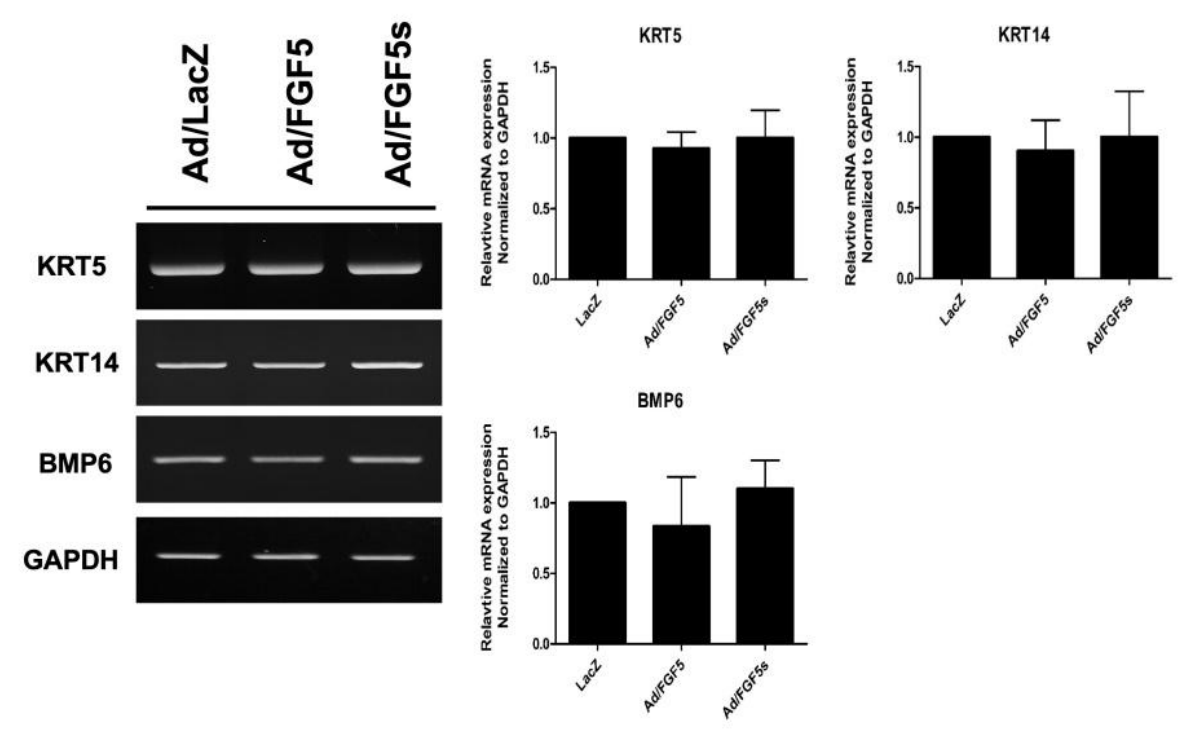

Fig-3: Gene expression directly associates with hair growth after FGF5 isoform overexpression in the SVKC. The graph data are shown the means \pm SD of three independent experiments

\section{DISCUSSION}

After overexpressing the FGF5 gene, the mRNA expression levels of the HGF, SCF, DKK1, and FGF2 were analyzed, respectively. HGF gene is a hormone secreted by mesenchymal cells and plays an important role in epithelial cells [21], it is known to regulate the interaction between dermal papilla and keratinocytes [22, 23], and promote DNA synthesis in hair bulbs. Through this study, it is estimated that FGF5s and HGF promote hair growth through interaction in gene or protein level [24].

FGF5 gene has been reported to regulate the degenerative phase in the late growth phase of the mammalian hair cycle $[10,16]$. In our study, long form of FGF5 tend to suppress expression of BMP6 in the group infected with Ad/FGF5 virus than in the control and Ad/FGF5s group. However, no significant difference was found in other genes, KRT5 and KRT14, which are the differentiation genes of external root sheath in the hair follicle.

Additional study showed that a significant increase was observed in the group treated with siRNA1 (C-terminal knockdown of FGF5) in BMP6, compared to the control group (data not shown). BMP6 acts as an inhibitor in the inner bulge, and the hair cycle enters the growth phase from the degenerative phase [25]. It is presumed that BMP6 could affect hair growth by inhibiting FGF5 activity when the C-terminus of the FGF5 gene is knocked down.

Taken together, FGF5s might activate HGF in hair growth and FGF5 may inhibit BMP6 expression in hair growth suppression.
Conflict of interest: Author declares that there is no conflict of interest in this study.

\section{REFERENCE}

1. Alonso, L., \& Fuchs, E. (2006). The hair cycle. J Cell Sci, 19:391-393.

2. Danilenko, D. M., Ring, B. D., Yanagihara. D., Benson, W., Wiemann, B., Starnes, C. O., \& Pierce. G. F. (1995). Keratinocyte growth factor is an important endogenous mediator of hair follicle growth, development, and differentiation. Normalization of the nu/nu follicular differentiation defect and amelioration of chemotherapy-induced alopecia. Am J Pathol, 147:145-154.

3. Green, M. R., \& Couchman. J. R. (1984). Distribution of epidermal growth factor receptors in rat tissues during embryonic skin development, hair formation, and the adult hair growth cycle. $J$ Invest Dermatol, 83:118-123.

4. Luetteke, N. C., Phillips, H. K., Qiu, T. H., Copeland, N. G., Earp, H. S., Jenkins, N. A., \& Lee, D. C. (1994). The mouse waved-2 phenotype results from a point mutation in the EGF receptor tyrosine kinase. Genes Dev, 8:399-413.

5. du Cros, D. L. (1993). Fibroblast growth factor influences the development and cycling of murine hair follicles. Dev Biol, 156:444-453.

6. Guo, L., Yu, Q. C., \& Fuchs, E. (1993) Targeting expression of keratinocyte growth factor to keratinocytes elicits striking changes in epithelial differentiation in transgenic mice. $E M B O \mathrm{~J}$, 12:973-986.

7. du Cros, D. L.(1993). Fibroblast growth factor and epidermal growth factor in hair development. $J$ Invest Dermatol, 101:106S-113S. 
8. du Cros, D. L., Isaacs, K., \& Moore, G. P. (1993). Distribution of acidic and basic fibroblast growth factors in ovine skin during follicle morphogenesis. J Cell Sci, 105:667-674.

9. Ozeki, M., \& Tabata, Y. (2002). Promoted growth of murine hair follicles through controlled release of basic fibroblast growth factor. Tissue Eng, 8:359-366.

10. Hébert, J. M., Rosenquist, T., Götz, J., \& Martin, G. R. (1994). FGF5 as a regulator of the hair growth cycle: evidence from targeted and spontaneous mutations. Cell, 78:1017-1025.

11. Paus, R. \& Foitzik, K. (2004). In search of the "hair cycle clock": a guided tour. Differentiation, 72:489-511.

12. Greco, V., Chen, T., Rendl, M., Schober, M, Pasolli, H. A., Stokes, N., Dela Cruz-Racelis, J., \& Fuchs, E. (2009). A two-step mechanism for stem cell activation during hair regeneration. Cell Stem Cell, 4:155-169.

13. Zhan, X., Culpepper, A., Reddy, M., Loveless, J., \& Goldfarb, M. (1987). Human oncogenes detected by a defined medium culture assay. Oncogene, 1:369-376.

14. Zhan, X., Bates, B., Hu, X. G., \& Goldfarb, M. (1988). The human FGF-5 oncogene encodes a novel protein related to fibroblast growth factors. Mol Cell Biol, 8:3487-3495.

15. Yoshiyuki, H., Masahiro Y., \& Nobuyuki, I. (1996). The rat FGF-5 mRNA variant generated by alternative splicing encodes a novel truncated form of FGF-5. Biochim Biophys Acta, 1306:3133.

16. Higgins, C. A., Petukhova, L., Harel, S., Ho. Y. Y., Drill, E., Shapiro, L., Wajid, M., \& Christiano, A. M. (2014). FGF5 is a crucial regulator of hair length in humans. Proc Natl Acad Sci USA, 111:10648-10653.

17. Ozawa, K., Suzuki, S., Asada, M., Tomooka, Y., Li, A. J., Yoneda, A., Komi, A., \& Imamura, T. (1998). An alternatively spliced fibroblast growth factor (FGF)-5 mRNA is abundant in brain and translates into a partial agonist/antagonist for FGF-5 neurotrophic activity. $J$ Biol Chem, 273:29262-29271

18. Suzuki, S., Ota, Y., Ozawa, K., \& Imamura, T. (2000) Dual-mode regulation of hair growth cycle by two Fgf-5 gene products. J Invest Dermatol, 114:456-463.

19. Yoon, H. K., Sohn, K. C,. Lee, J. S., Kim, Y. J., Bhak, J., Yang, J. M., You, K. H., Kim, C. D., \& Lee, J. H. (2008). Prediction and evaluation of protein-protein interaction in keratinocyte differentiation. Biochem Biophys Res Commun, 377:662-667.

20. Wafa, L. A., Cheng, H., Rao, M. A., Nelson, C. C., Cox, M., Hirst, M., Sadowski, I., \& Rennie, P. S. (2003). Isolation and identification of L-dopa decarboxylase as a protein that binds to and enhances transcriptional activity of the androgen receptor using the repressed transactivator yeast two-hybrid system. Biochem J, 375:373-383.

21. Ohmichi, H., Koshimizu, U., Matsumoto, K., \& Nakamura, T. (1998). Hepatocyte growth factor (HGF) acts as a mesenchyme-derived morphogenic factor during fetal lung development. Development, 125:1315-1324.

22. Fujie, T., Katoh, S., Oura, H., Urano, Y., \& Arase, S. (2001). The chemotactic effect of a dermal papilla cell-derived factor on outer root sheath cells. J Dermatol Sci, 25:206-212.

23. Lindner, G., Botchkarev, V. A., Botchkareva, N. V., Ling, G., van der Veen, C., \& Paus, R. (1997). Analysis of apoptosis during hair follicle regression (catagen). Am J Pathol, 151:1601-1617.

24. Shimaoka, S., Tsuboi, R., Jindo, T., Imai, R., Takamori, K., Rubin, J. S., \& Ogawa, H. (1995). Hepatocyte growth factor/scatter factor expressed in follicular papilla cells stimulates human hair growth in vitro. J Cell Physiol, 165:333-338.

25. Lee, J., \& Tumbar, T. (2012). Hairy tale of signaling in hair follicle development and cycling. Seminars in Cell \& Developmental Biol, 23: 906916. 